\title{
Purification, Characterization, and Molecular Cloning of Gonadotropin Subunits of Silver Carp (Hypophthalmichthys molitrix)
}

\author{
Y. S. Chang, C. J. Huang, F. L. Huang, C. S. Liu, and T. B. Lo \\ Institute of Biological Chemistry, Academia Sinica and Institute of Biochemical Science, National Taiwan \\ University, P.O. Box 23-106, Taipei, Taiwan
}

Accepted May 17, 1989

\begin{abstract}
The $\alpha$ and $\beta$ subunit of silver carp gonadotropin (scGTH- $\alpha$ and scGTH- $\beta$ ) were isolated by high-performance liquid chromatography. Heterogeneity of $\mathrm{N}$-terminal amino acid sequence was observed in scGTH- $\alpha$ but not in scGTH- $\beta$. For determining the complete primary structures of scGTH- $\alpha$ and scGTH- $\beta$, their cDNAs were cloned. Combining the data of Nand $\mathrm{C}$-terminal sequences determined from proteins and the amino acid sequences deduced from cDNAs, we infer that scGTH- $\alpha$ consists of 95 and/or 93 residues and scGTH- $\beta$ consists of 115 residues. Both scGTH- $\alpha$ and scGTH- $\beta$ are glycoprotein. Their carbohydrate content is about $20 \mathrm{~g}$ per $100 \mathrm{~g}$ protein. The molecular weights of scGTH- $\alpha$ and scGTH- $\beta$ were calculated to be 12,700 and $15,700 \mathrm{Da}$, respectively. The amino acid sequences of scGTH- $\alpha$ and scGTH- $\beta$ are very similar to those of the corresponding subunit of carp GTH, different in only 2 and 4 residues, respectively. In addition, a high extent of homology (70\%) was also observed between the $\alpha$ subunits of fish and mammalian GTHs. In the case of $\beta$ subunit, homology among various species of fish (75 to $98 \%$ ) is much higher than that between fish and mammal (40\%). These data suggest that the $\alpha$ subunit is conserved while the $\beta$ subunit is diversified during the molecular evolution of vertebrate GTH. 1990 Academic Press, Inc
\end{abstract}

Mammalian anterior pituitary gland synthesizes and secretes three glycoprotein hormones. They are luteinizing hormone (LH), follicle-stimulating hormone (FSH), and thyroid-stimulating hormone (TSH). The former two are collectively designated as gonadotropin (GTH). All of them consist of two nonidentical subunits, the $\alpha$ and $\beta$ subunit. Upon nonconvalent association of these two subunits, hormonal function is achieved. Within a given species, all of these glycoprotein hormones share the same $\alpha$ subunit while the $\beta$ subunit is hormone specific (see review of Pierce and Parsons, 1981). Like mammalian GTH, teleostean GTH is also synthesized and secreted from anterior pituitary gland and composed of two nonidentical subunits. The function of teleostean GTH on gametogenesis and steroidogenesis has been well documented (see review of Idler and $\mathrm{Ng}$, 1983).
The primary structures of the $\alpha$ and $\beta$ subunits of mammalian GTHs from several species had been reported (see review of Pierce and Parsons, 1981). Comparison of known sequences of $\alpha$ subunits indicates that they are highly conserved from species to species. Similarly, homology between $\beta$ subunit is also apparent. There are regions of striking conservation, not only for the same hormone between species, but also between hormones.

The $\alpha$ and $\beta$ subunits of GTH from several species of teleost have been purified and characterized (Burzawa-Gerard, 1974; Chang et al., 1988b; Huang et al., 1982; Itoh et al., 1988; Suzuki et al., 1988; Trinh et al., 1986). Compared to those of mammalian GTHs, the primary structures of the $\alpha$ and $\beta$ subunits of fish GTH are not so extensively studied. Up to now, only the complete sequence of the $\alpha$ subunit of carp GTH (cGTH- $\alpha$ ) and the $\beta$ subunit of cGTH 
(cGTH- $\beta$ ) (Chang et al., 1988b) and salmon GTH (sGTH- $\beta$ ) (Itoh et al., 1988; Trinh et al., 1986) have been determined or deduced from the nucleotide sequence of cDNA. The comparative data show that there is a high extent of homology (70\%) in amino acid sequence existing among the $\alpha$ subunit of carp and mammalian GTHs. As for the $\beta$ subunit, the homology between CGTH and sGTH is high (75\%) while that between fish GTH and mammalian GTH is low (40\%). Such findings suggest that the $\alpha$ subunit is conserved while the $\beta$ subunit is diversified during the molecular evolution of vertebrate GTH.

The above findings are only based on the data of two species of fish. In order to provide a wider basis for comparative study, we are attempting to determine the primary structures of the $\alpha$ and $\beta$ subunit of GTHs from more species of fish. This paper is one of a series of such studies. Here, we report the purification and characterization of the $\alpha$ and $\beta$ subunit of GTH (scGTH- $\alpha$ and scGTH- $\beta$ ) from silver carp (Hypophthalmichthys molitrix) and the determination of their primary structures by molecular cloning.

\section{MATERIALS AND METHODS}

Purification of scGTH- $\alpha$ and scGTH- $\beta$. The scGTH was purified as previously described (Chang et al., 1988a). Purification of scGTH- $\alpha$ and scGTH- $\beta$ was performed by high-performance liquid chromatography (HPLC). The scGTH was dissolved in $\mathrm{H}_{2} \mathrm{O}$ and chromatographed through a Nucleosil $\mathrm{C}_{18}$ column (4.6 $\times 250 \mathrm{~mm}, 7 \mu \mathrm{m})$ equilibrated with solvent A (22.5\% acetonitrile- $0.07 \%$ trifluoroacetic acid, TFA) and eluted by a linear gradient of solvent B $(40 \%$ acetonitrile- $0.07 \%$ TFA) in which $70 \%$ of solvent $B$ was achieved at $60 \mathrm{~min}$. The flow rate was $1 \mathrm{ml} / \mathrm{min}$. Operation of HPLC was performed at $40^{\circ}$. Individual peak was collected and recovered by lyophilization.

Bioassay of scGTH- $\alpha$ and scGTH- $\beta$. The GTH activities of scGTH- $\alpha$ and scGTH- $\beta$ and their recombinant were assayed by the method of androgen production by carp testis in vitro as previously described (Huang and Chang, 1980). Reassociation of scGTH- $\alpha$ and scGTH- $\beta$ was performed by mixing them at a 1:1 molar ratio (final concentration, $1 \mathrm{mg} / \mathrm{ml}$ ) in $50 \mathrm{mM}$

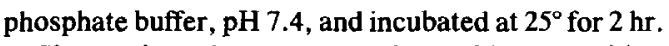
Chemical analyses. The amino acid composition was determined by the method as described by Chang and Liu (1988). The N-terminal amino acid sequence was determined by a $477 \mathrm{~A}$ protein sequencer and an on-line 120A phenylthiohydantoin analyzer of Applied Biosystems, Foster City, California (Hewick et al., 1981). For determination of C-terminal amino acid sequence, scGTH- $\alpha$ and scGTH- $\beta$ were digested with carboxypeptidase Y (Millipore Corp., Bedford, MA) (substrate:enzyme, 30:1, w/w) in $50 \mathrm{mM}$ pyridineacetate, $\mathrm{pH} 5.4$, at $37^{\circ}$ for 0,10 , and $20 \mathrm{~min}$ by the method of Hayashi (1977). The enzymatic digestion was stopped by the addition of acetic acid. After drying, released amino acids were converted to dimethylaminoazobenzene sulfonyl(DABSYL)aminoacid and analyzed (Knecht and Chang, 1986). The carbohydrate content was estimated by using the thiobarbituric acid method for sialic acid (Warren, 1959), the orcinol reaction for neutral sugar (Winzler, 1955), and the pdimethylaminobenzaldehyde reaction for amino sugar (Rondle and Morgan, 1955). The sodium dodecyl sulfate (SDS)-polyacrylamide gel electrophoresis (PAGE) was performed as described by Laemmli (1970). The scGTH and its subunits were quantified by their protein content determined by the method of Lowry et al. (1951) with bovine serum albumin as reference.

Radioimmunoassay. The scGTH $\alpha$ and scGTH- $\beta$ were used as antigen to induce antisera in rabbit by multiple-site injection (Vaitukaitis et al., 1971). Iodination of protein was performed by the chloramine- $T$ method (Greenwoods et al., 1963). For assay, 10,000 $\mathrm{cpm}$ of labeled antigen and a proper dilution of antiserum which bound $30 \%$ of labeled antigen in the absence of unlabeled antigen were used. The assay conditions were essentially the same as those described by Roser et al. (1984).

Construction of cDNA library. The polyadenylated mRNA of silver carp pituitary glands was prepared from liquid nitrogen frozen tissue by the guanidinium/ $\mathrm{CsCl}$ method (Ullrich et al., 1977) followed by oligodT cellulose column chromatography. Doublestranded $\mathrm{CDNA}$, synthesized by the method of Gubler and Hoffman (1983), was ligated with EcoRI linker and subsequently inserted into the EcoRI site of pUC 19. The Escherichia coli strain JM 101 was used as host.

Screening of cDNA library. The cDNAs encoding cGTH- $\alpha$ and cGTH- $\beta$ (Chang $e t$ al., 1988b) were used as probes to screen the cDNA coding for scGTH- $\alpha$ and scGTH- $\beta$, respectively. The cDNAs used for probes were labeled with ${ }^{32} \mathrm{P}$-dATP by nick translation.

Bacteria containing recombinant plasmids were first grown on nitrocellulose filter, lysed with $\mathrm{NaOH}$, baked, and then hybridized by the method of Grunstein and Hogness (1975). For further confirmation the plasmid DNAs of positive clones were extracted and 
digested with EcoRI, subsequently subjected to electrophoresis in agarose, and then hybridized in situ with labeled probes (Kidd et al., 1983).

DNA sequence analysis. In order to analyze the complete nucleotide sequences of the cloned cDNAs, they were further subcloned. The cDNAs enconding scGTH- $\alpha$ and scGTH- $\beta$ were cleaved with PstI and AvaII, respectively. After separation by electrophoresis in agarose and electroelution, the resulted DNA fragments were subcloned into pUC 19. The nucleotide sequences were determined by the dideoxynucleotide chain termination method (Sanger et al., 1977).

\section{RESULTS}

\section{Isolation of scGTH- $\alpha$ and scGTH- $\beta$}

By the HPLC system used in this study, scGTH could be resolved into four major peaks (Fig. 1). When they were analyzed by SDS-PAGE, peaks 1,3 , and 4 showed one electrophoretic band while peak 2 showed

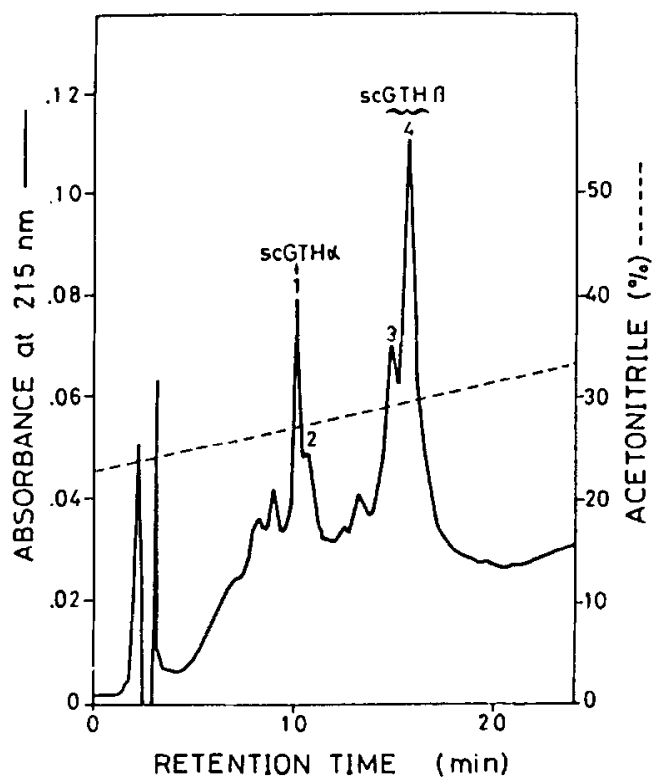

FIG. 1. Reverse-phase HPLC fractionation of the subunits of silver carp GTH. Ten micrograms of scGTH dissolved in $\mathrm{H}_{2} \mathrm{O}$ was loaded onto a Nucleosil $\mathrm{C}_{18}$ column $(4.6 \times 250 \mathrm{~mm}, 7 \mu \mathrm{m})$ equilibrated with solvent A (22.5\% acetonitrile- $0.07 \%$ trifluoroacetic acid, TFA). The sample was eluted with a linear gradient in which $70 \%$ of solvent $B(40 \%$ acetonitrile $-0.07 \%$ TFA) was reached at $60 \mathrm{~min}$ at a flow rate of $1 \mathrm{ml} / \mathrm{min}$. Operation of HPLC was performed at $40^{\circ}$. two electrophoretic bands. As described below, the $\mathrm{N}$-terminal amino acid sequence analysis indicated that peak 1 had a similar sequence to that of cGTH- $\alpha$ while peaks 3 and 4 had a similar sequence to that of cGTH- $\beta$ (Table 1). Consequently, peak 1 was designated as scGTH- $\alpha$ and peaks 3 and 4 were collectively designated as scGTH- $\beta$.

GTH Acitivity of scGTH- $\alpha, s c G T H-\beta$, and Their Recombinant

As shown in Fig. 2, either scGTH- $\alpha$ or scGTH- $\beta$ expressed very low GTH activity while the recombinant of scGTH- $\alpha$ and scGTH- $\beta$ expressed high GTH activity fully comparable to native scGTH when assayed by androgen production by carp testis in vitro. These results further indicate that $\operatorname{scGTH}-\alpha$ and scGTH- $\beta$ isolated by HPLC are the two different subunits of scGTH.

\section{Radioimmunoassay}

In order to further characterize scGTH- $\alpha$ and scGTH- $\beta$, an immunological approach was also undertaken. Antiserum against scGTH- $\alpha$ (AS- $\alpha$ ) and that against scGTH- $\beta$ (AS- $\beta$ ) were induced in rabbit. Both AS- $\alpha$ and As- $\beta$ reacted strongly to the homologous antigen but weakly to the heterologous antigen. Calculated at $B / B_{O}=50 \%$, AS- $\alpha$ showed $3.7 \%$ cross-reactivity toward scGTH- $\beta$ while As- $\beta$ showed $5.6 \%$ crossreactivity toward ScGTH- $\alpha$ (data not shown).

\section{Chemical Properties of scGTH- $\alpha$ and scGTH- $\beta$}

The amino acid composition, carbohydrate content, and $\mathrm{N}$ - and $\mathrm{C}$-terminal amino acid sequence of scGTH- $\alpha$ and scGTH- $\beta$ are presented in Table 1. Both scGTH- $\alpha$ and scGTH- $\beta$ had high content of Asp/Asn, Glu/Gln, Pro, and half Cys. In comparison, the scGTH- $\alpha$ contains more basic but less 


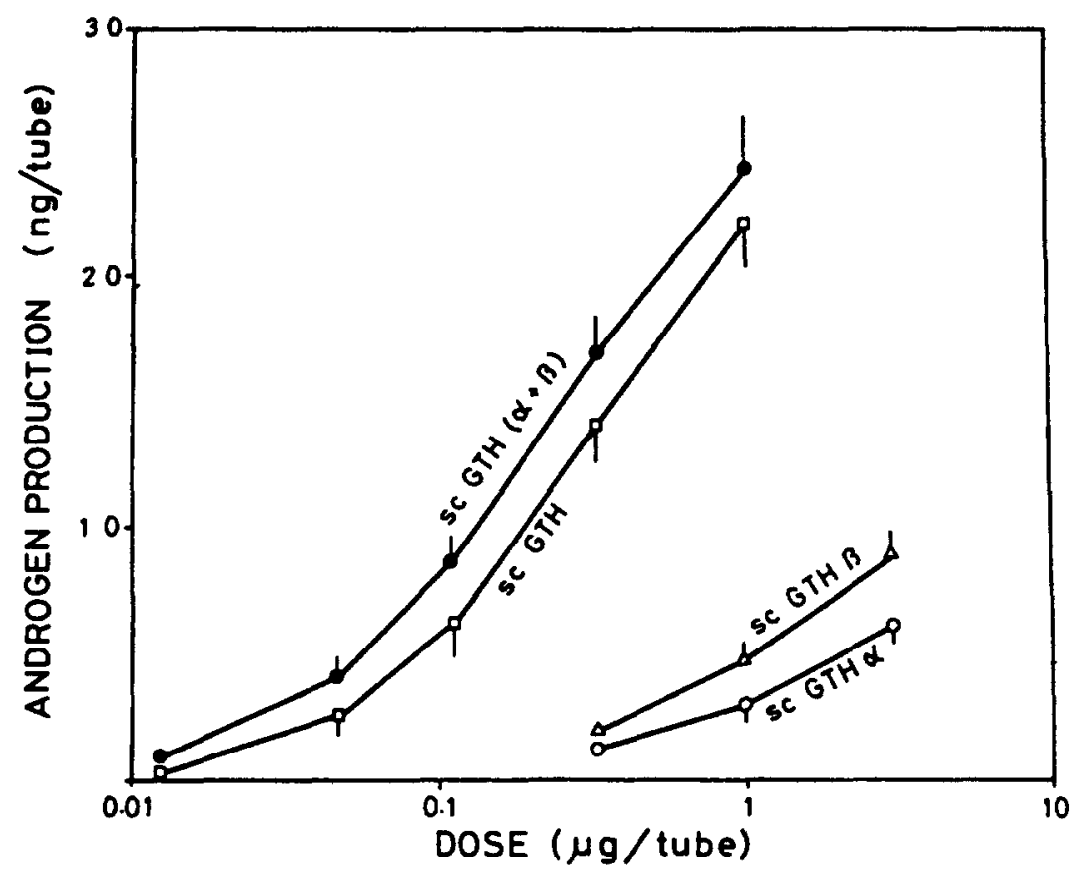

FIG. 2. The GTH activities of native scGTH, its $\alpha$ and $\beta$ subunits, and the recombinant of $\alpha$ and $\beta$ subunits. The method of androgen production by carp testis in vitro (Huang and Chang, 1980) was used for assay of GTH activity. Each point is the mean of three incubations. Vertical line indicates standard deviation.

acidic amino acid residues than scGTH- $\beta$. In addition, scGTH- $\alpha$ had a lower carbohydrate content than scGTH- $\beta$, mainly attributable to amino sugar.

The amino acid sequence analysis indicated heterogeneity in $\mathrm{N}$-terminal sequence was observed in scGTH- $\alpha$ but not in scGTH- $\beta$. Two forms of scGTH- $\alpha$ were found, one with Tyr-Pro-Arg-Asn-Aspwhile the other one had Arg-Asn-Asp- as their N-terminal sequence. For scGTH- $\beta$, the $\mathrm{N}$-terminal sequence was identified to be Ser-Phe-Leu-Pro-Pro-. The C-terminal sequences of scGTH- $\alpha$ and scGTH- $\beta$ were determined to be -Lys-Ser and -Phe-Pro, respectively. The molecular weights of scGTH- $\alpha$ and scGTH- $\beta$ estimated by SDSPAGE were 17,400 and 22,670 Da, respectively. However, these values are different from those calculated by summing up the molecular weights of constituting amino acid residues and carbohydrate content of the molecule, which yielded $12,700 \mathrm{Da}$ for scGTH- $\alpha$ and 15,700 Da for scGTH- $\beta$.

Nucleotide Sequencing of cDNA Encoding scGTH- $\alpha$

From 548 recombinant cDNA clones, 4 positive clones were obtained when cDNA encoding cGTH- $\alpha$ was used as a probe. The nucleotide sequence and the deduced amino acid sequence of one cDNA encoding scGTH- $\alpha$ are presented in Fig. 3. As shown in Fig. 3, it has 869 base pairs (bp) in length, consisting of $31 \mathrm{bp}$ of the $5^{\prime}$ untranslated region, $354 \mathrm{bp}$ of the open reading frame, and $481 \mathrm{bp}$ of the $3^{\prime}$ untranslated region. The open reading frame encodes a polypeptide of 118 residues which contains a 95residue protein with the same $\mathrm{N}$ - and $\mathrm{C}$ terminal sequences as those determined from scGTH- $\alpha$. The amino acid composition predicted from cDNA is very close to that determined from scGTH- $\alpha$ (Table 1). 
TABLE 1

The Chemical Properties of scGTH- $\alpha$ and scGTH- $\beta$

\begin{tabular}{|c|c|c|c|c|}
\hline & \multicolumn{2}{|c|}{$\alpha$ subunit } & \multicolumn{2}{|c|}{$\beta$ subunit } \\
\hline & Protein $^{a}$ & $\mathrm{cDNA}^{b}$ & Protein $^{a}$ & $\mathrm{cDNA}^{b}$ \\
\hline \multicolumn{5}{|c|}{ Amino acid composition ${ }^{c}$} \\
\hline Lys & $9.2(9)$ & 10 & $4.0 \quad(4)$ & 4 \\
\hline His & $3.2(3)$ & 3 & 3.0 & 3 \\
\hline Arg & 3.9 (4) & 4 & $4.1 \quad(4)$ & 4 \\
\hline Asx & $10.2(10)$ & 10 & $9.1 \quad(9)$ & 9 \\
\hline Thr & $6.6(7)$ & 7 & $10.3(10)$ & 11 \\
\hline Ser & $5.8 \quad(6)$ & 6 & $7.6 \quad(8)$ & 9 \\
\hline Glx & $6.3(6)$ & 6 & $11.6(12)$ & 12 \\
\hline Pro & $6.4(6)$ & 6 & $13.2(13)$ & 13 \\
\hline Gly & 3.7 (4) & 3 & $4.1 \quad(4)$ & 3 \\
\hline Ala & $4.7(5)$ & 4 & $2.7 \quad(3)$ & 2 \\
\hline $1 / 2 \mathrm{Cys}$ & $9.6(10)$ & 10 & 12.1 (12) & 12 \\
\hline Val & $8.4(8)$ & 8 & 11.4 (11) & 11 \\
\hline Met & $1.9(2)$ & 2 & $2.0 \quad(2)$ & 2 \\
\hline Ile & $2.9(3)$ & 3 & $3.2 \quad(3)$ & 3 \\
\hline Leu & $5.4(5)$ & 5 & $7.1 \quad(7)$ & 7 \\
\hline Tyr & $4.2(4)$ & 5 & $5.6 \quad(6)$ & 6 \\
\hline Phe & $3.0(3)$ & 3 & $4.0 \quad(4)$ & 4 \\
\hline Total & (95) & 95 & (115) & 115 \\
\hline \multicolumn{5}{|c|}{ Amino acid sequence } \\
\hline $\begin{array}{l}\text { N-terminal } \\
\text { C-terminal }\end{array}$ & \multicolumn{2}{|c|}{$\begin{array}{c}\text { (Tyr-Pro)-Arg-Asn-Asp- } \\
\text {-Lys-Ser }\end{array}$} & \multicolumn{2}{|c|}{$\begin{array}{c}\text { Ser-Phe-Leu-Pro-Pro- } \\
\text {-Phe-Pro }\end{array}$} \\
\hline \multicolumn{5}{|c|}{ Carbohydrate content $^{d}$} \\
\hline Neutral sugar & \multicolumn{2}{|c|}{10.2} & \multicolumn{2}{|c|}{10.6} \\
\hline Amino sugar & \multicolumn{2}{|c|}{6.6} & \multicolumn{2}{|c|}{11.2} \\
\hline Sialic acid & \multicolumn{2}{|c|}{1.3} & \multicolumn{2}{|c|}{2.1} \\
\hline
\end{tabular}

a Determined from protein by amino acid analysis.

${ }^{b}$ Predicted from nucleotide sequence of cDNA.

${ }^{c}$ Number of residues. The integrated number is shown in parentheses.

${ }^{d} \mathrm{~g}$ per $100 \mathrm{~g}$ protein.

\section{Nucleotide Sequencing of $c D N A$ Encoding scGTH $-\beta$}

There are three positive clones obtained when cDNA encoding $\mathrm{cGTH}-\beta$ was used as a probe for screening of the silver carp pituitary cDNA library. The nucleotide and deduced amino acid sequence of one cDNA encoding scGTH- $\beta$ are presented in Fig. 4. It has $554 \mathrm{bp}$ in length, consisting of $18 \mathrm{bp}$ of the $5^{\prime}$ untranslated region, $423 \mathrm{bp}$ of the open reading frame, and $110 \mathrm{bp}$ of the $3^{\prime}$ untranslated region. The open reading frame encodes a 115-residue protein with the same $\mathrm{N}$ - and $\mathrm{C}$-terminal sequences as those determined from scGTH- $\beta$. The data of Table 1 also indicated that the amino acid composition predicted from CDNA is very close to that determined from scGTH- $\beta$.

\section{DISCUSSION}

The scGTH has been purified and characterized (Chang et al., 1988a). In this paper, we continued our previous work to purify and characterize the subunits of scGTH for the purpose of getting a better understanding of scGTH and of providing a wider basis for comparative study of vertebrate GTHs.

The two subunits of scGTH prepared in this study seem to be highly purified, as 


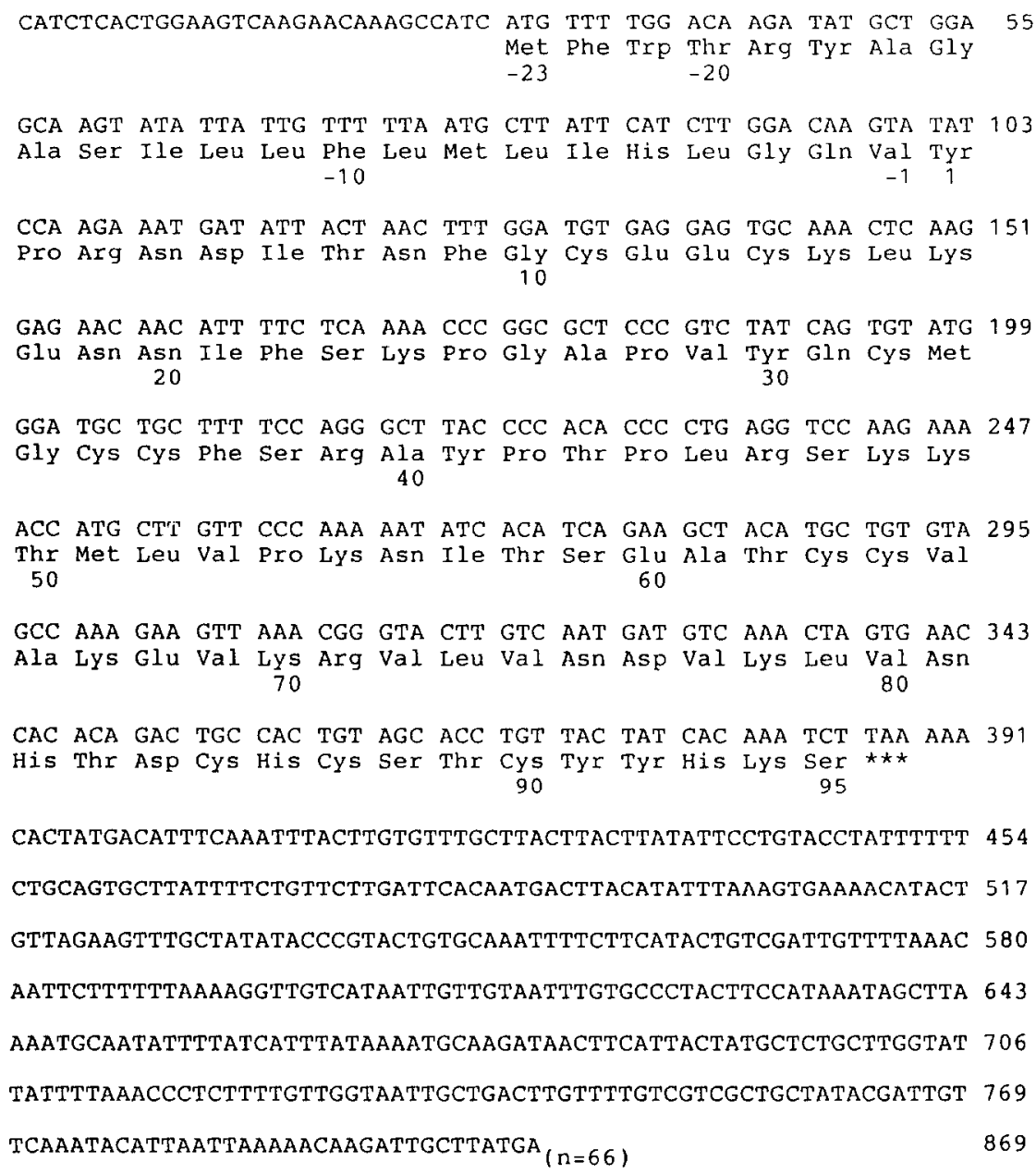

Fig. 3. The nucleotide sequence and the deduced amino acid sequence of cDNA encoding scGTH- $\alpha$.

evidenced by the following criteria: (1) Both scGTH- $\alpha$ and scGTH- $\beta$ have only one electrophoretic band in SDS-PAGE; (2) reassociation of scGTH- $\alpha$ and scGTH- $\beta$ could fully restore the hormonal function (Fig. 2); (3) the antiserum against scGTH- $\alpha$ and that against scGTH- $\beta$ had very low cross-reactivity toward their counterpart subunits; and (4) both scGTH- $\alpha$ and scGTH- $\beta$ have their own unique $N$ - and $C$ terminal sequence (Table 1). However, it should be noted that heterogeneity is found in the $\mathrm{N}$-terminal sequence of scGTH- $\alpha$.
Such phenomenon was also observed in the case of ovine LH- $\alpha$ (Liu et al., 1972).

Molecular cloning has been widely used to determine the primary structure of protein. Combining the data of $\mathrm{N}$ - and $\mathrm{C}$ terminal sequences determined from protein and the amino acid sequence deduced from cDNA, we infer that scGTH- $\alpha$ has 95 and/or 93 residues while scGTH- $\beta$ has 115 residues. The $C$-terminal residue of scGTH- $\alpha$ is the same one just preceding the stop codon while that of scGTH- $\beta$ is the one which is two residues ahead of the stop 


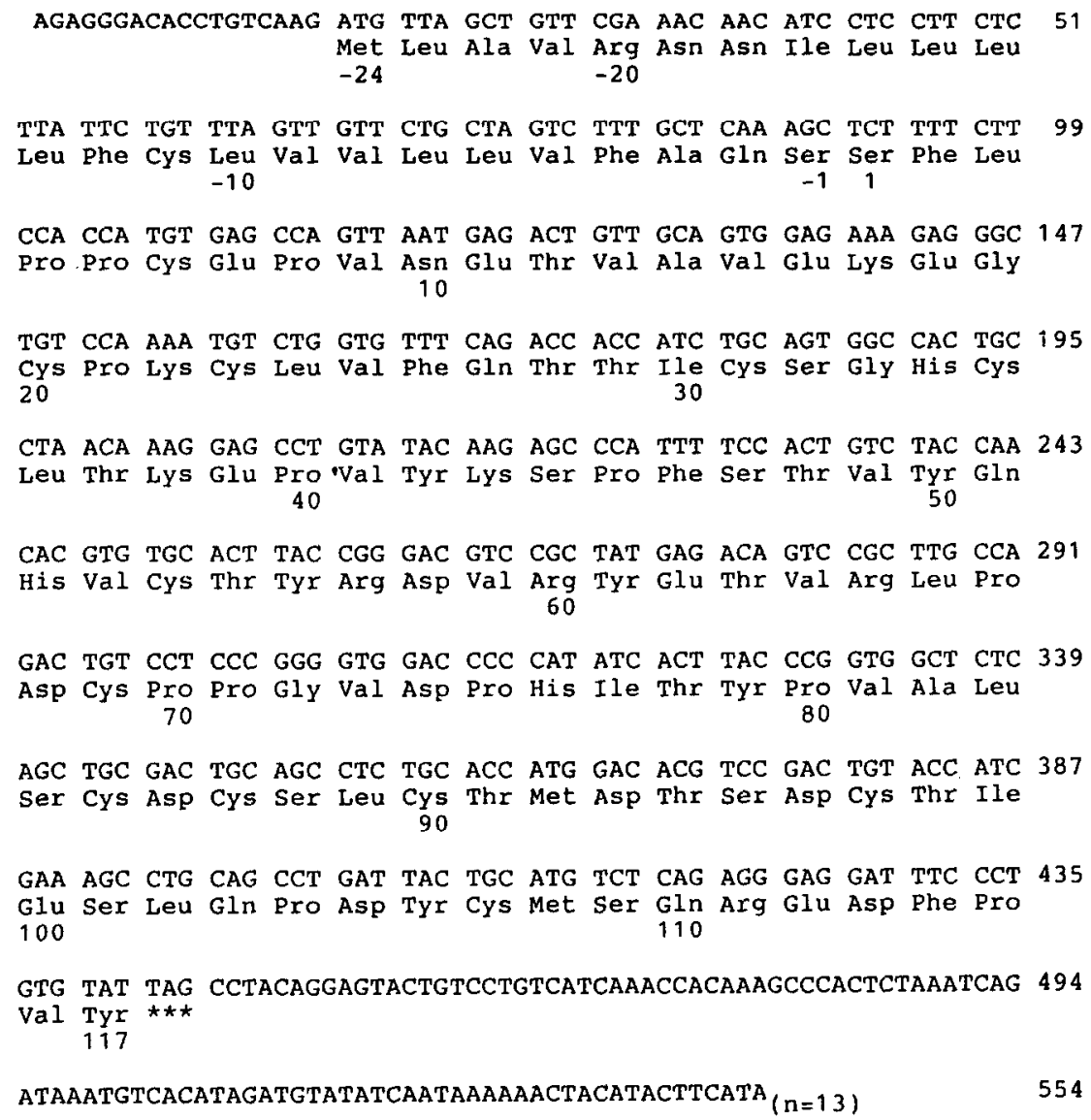

FIG. 4. The nucleotide sequence and the deduced amino acid sequence of cDNA encoding scGTH-B.

codon. Consequently, there must be a posttranslational modification of scGTH- $\beta$ by proteolytic cleavage of two residues ( $\mathrm{Va}-$ Tyr) from the precursor. Post-translational modification at the C-terminal part is also observed in cGTH- $\beta$ (Chang et al., 1988b) and mammalian LH- $\beta$ (Maurer, 1985) and TSH- $\beta$ (Maurer $e t$ al., 1984), but not in

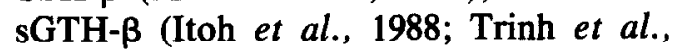
1986) and mammalian FSH- $\beta$ (Esch et al., 1986).

Recently, two distinct GTHs, designated as GTH I and II, from chum salmon pituitary glands were isolated by Suzuki $e t$ al. (1988). They share a common $\alpha$ subunit but have a different $\beta$ subunit. The homology of the amino acid sequence between these two subunits is very low, only about $30 \%$ (Itoh et al., 1988). Therefore, duality of GTH was hypothesized. However, only one type of GTH was isolated and characterized from other species of fish, including silver carp (Burzawa-Gerard, 1974; Chang et al., 1988a,b; Donaldson et al., 1972; Farmer and Papkoff, 1977; Huang et al., 1981; Pierce et al., 1976). Such discrepancy may be due to either species differences or different methods used for GTH extraction and purification. If two types of $\beta$ subunits of GTH are present in silver carp, then two types of corresponding cDNAs should be expected. Because the probe we used for 
screening scGTH- $\beta$ was the cDNA encoding cGTH $-\beta$, which is highly homologous to the $\beta$ subunit of salmon GTH II, therefore only one type of cDNA encoding scGTH- $\beta$ was obtained. In order to investigate whether duality of GTH is also present in silver carp or not, we are currently rescreening the cDNA library of silver carp with other probes.

The amino acid sequence of scGTH- $\alpha$ is very similar to that of cGTH- $\alpha$, with a difference of 2 residues. In addition, scGTH- $\alpha$ bears a high extent of homology $(72 \%)$ to that of the $\alpha$ subunit of mammalian glycoprotein hormones (Tables 2 and 4). The extent of homology between the $\alpha$ subunit of fish and mammalian GTH is close to that between the $\alpha$ subunit of pituitary glycoprotein hormones from different species of mammal. Like the $\alpha$ subunit, homology of amino acid sequences between scGTH- $\beta$ and $c$ GTH- $\beta$ is extremely high, only different in 4 residues. When scGTH- $\beta$ is compared with sGTH- $\beta$, the homology in the amino acid sequence decreased to $75 \%$ (Table 4). The $\beta$ subunit of Cyprinidae GTH (scGTH and cGTH) and Salmonidae GTH (sGTH) share a long homologous region in the middle part of the molecule (Table 3). However, their $\mathrm{N}$ - and $\mathrm{C}$-terminal sequences are different from each other. These results reveal the phylogenetic rela-

TABLE 2

The Amino Acid Sequences of the $\alpha$ Subunit of Silver Carp and Carp GTH and Human aNd Bovine LH

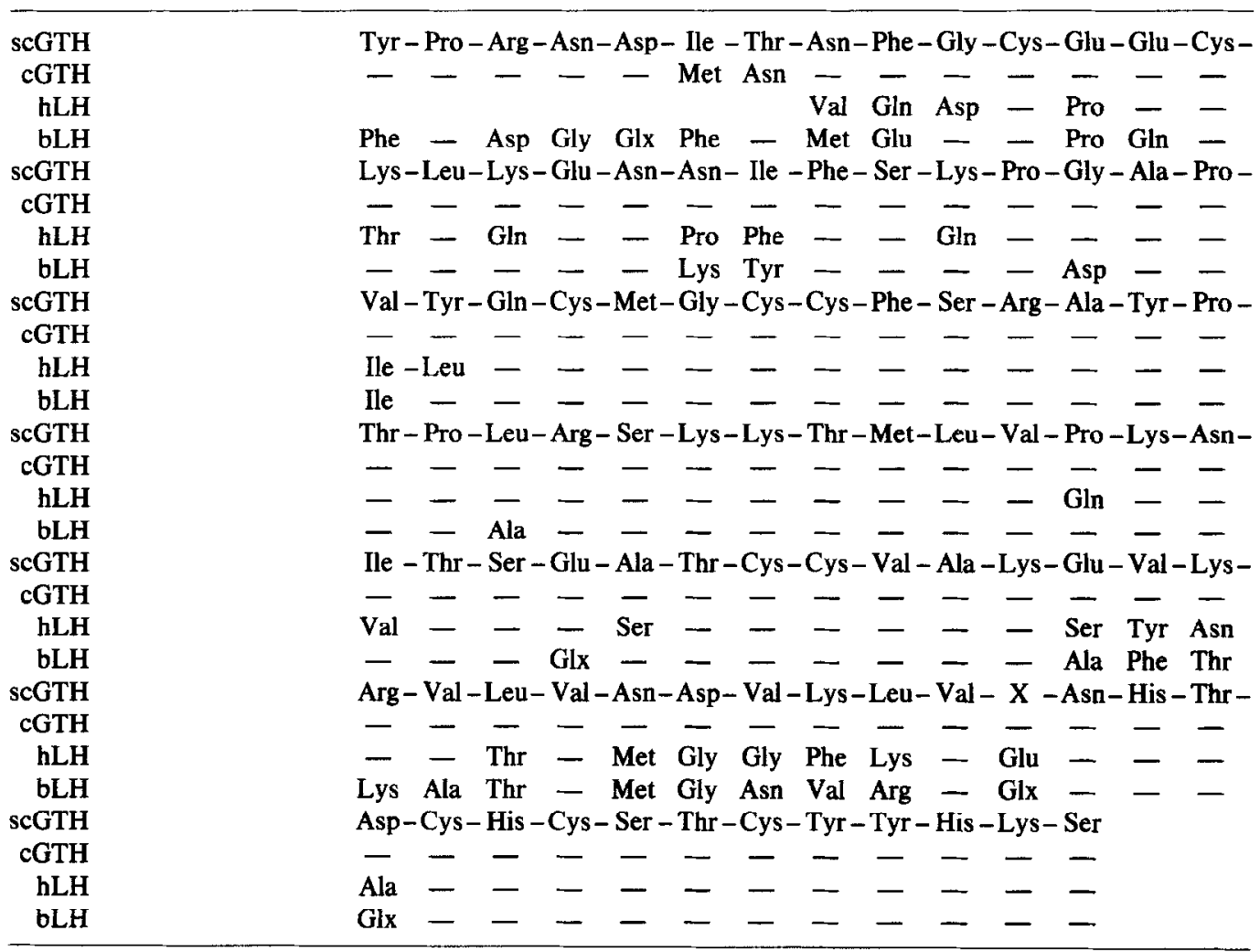

Note. sc, silver carp; c, carp; h, human; b, bovine; -, residue identical to that of scGTH; X, gap insertion for half cystine alignment. References: cGTH from Chang et al. (1988b); hLH from Fiddes and Talmadge (1984); bLH from Cornell and Pierce (1974). 
TABLE 3

The Amino Acid Sequences of the $\beta$ Subunit of Silver Carp, Carp, and Salmon GTH AND Bovine LH AND FSH

\begin{tabular}{|c|c|c|c|c|c|c|c|c|c|c|c|c|c|c|}
\hline scGTH & & & & Ser - & Phe- & -Leu & Pro. & - Pro & -Cys & Glu_- & Pro - & Val & -Asn- & -Glu _ \\
\hline cGTH & & & & - & Tyr & - & - & - & - & - & - & - & - & - \\
\hline sGTH & & & & - & Leu & Met & Gln & - & - & Gln & - & Ile & - & Gln \\
\hline bLH & Ser - & Arg - & -Gly & - Pro & Leu & Arg & - & Leu & - & Gln & - & Ile & - & Ala \\
\hline bFSH & & & & & & & & & - & - & Leu & Thr & - & Ile \\
\hline scGTH & Thr - & Val - & - Ala & - Val - & - Glu - & -Lys - & Glu & - Gly - & -Cys & Pro - & -Lys - & -Cys & -Leu- & - Val - \\
\hline cGTH & - & - & - & - & - & - & - & - & - & - & - & - & - & - \\
\hline sGTH & - & - & Ser & Leu & - & - & - & - & - & - & Thr & - & - & - \\
\hline bLH & - & Leu & - & $\mathrm{Ala}$ & - & - & - & Ala & - & - & Val & - & Ile & Thr \\
\hline bFSH & - & Ile & Thr & - & - & - & - & Glu & - & Gly & Phe & - & Ile & Ser \\
\hline scGTH & Phe- & $G \ln -$ & - Thr - & - Thr - & - Ile - & -Cys - & - Ser & -Gly_ & - His & -Cys- & -Leu- & Thr & -Lys- & -Glu - \\
\hline cGTH & Leu & - & - & - & - & - & - & - & - & - & - & - & - & - \\
\hline sGTH & Ile & Arg & Ala & Pro & - & - & - & - & - & - & Val & - & - & - \\
\hline bLH & - & Thr & - & Ser & - & - & Ala & - & Tyr & - & Pro & Ser & Met & Lys \\
\hline bFSH & Ile & Asn & - & - & Trp & - & $\mathrm{Ala}$ & - & Tyr & - & Tyr & - & Arg & Asp \\
\hline scGTH & Pro - & Val - & - Tyr - & -Lys- & - Ser - & Pro - & Phe & - Ser - & -Thr & - Val - & - Tyr - & Gln & - His - & - Val - \\
\hline cGTH & - & - & - & - & - & - & - & - & - & - & - & - & - & - \\
\hline sGTH & - & - & Phe & - & - & - & - & - & - & - & - & - & - & - \\
\hline bLH & Arg & - & Leu & Pro & Val & Ile & Leu & Pro & Pro & Met & Pro & - & Arg & - \\
\hline bFSH & Leu & - & - & Arg & Asp & - & Ala & Arg & Pro & Asn & Ile & - & Lys & Thr \\
\hline scGTH & Cys- & Thr - & - Tyr - & -Arg & -Asp- & - Val & -Arg & - Tyr - & - Glu & - Thr - & - Val & Arg & -Leu- & -Pro- \\
\hline cGTH & - & - & - & - & - & - & - & - & - & - & - & - & - & - \\
\hline sGTH & - & - & - & - & - & - & - & - & - & Met & Ile & - & - & - \\
\hline bLH & - & $\rightarrow$ & - & His & Glu & Leu & - & Phe & Ala & Ser & - & - & - & - \\
\hline bFSH & - & - & Phe & Lys & Glu & Leu & Val & - & - & - & - & Lys & Val & - \\
\hline scGTH & Asp- & Cys - & - Pro - & Pro - & -Gly - & - Val - & Asp & - Pro - & - His & - Ile - & - Thr & -Тyг & - Pro & $-\mathrm{Val}-$ \\
\hline cGTH & - & - & - & - & - & - & - & - & - & - & - & - & - & - \\
\hline sGTH & - & - & - & - & Trp & Ser & - & - & - & Val & - & - & - & - \\
\hline bLH & Gly & - & - & - & - & - & - & - & Met & Val & Ser & Phe & - & - \\
\hline bFSH & Gly & - & Ala & His & His & Ala & - & Ser & Leu & Туг & - & - & - & - \\
\hline scGTH & Ala - & Leu- & - Ser & -Cys - & -Asp- & -Cys- & - Ser & -Leu- & -Cys & - Thr - & -Met- & Asp & - Thr - & - Ser - \\
\hline cGTH & - & - & - & - & - & - & - & - & - & - & - & - & - & - \\
\hline sGTH & - & - & - & - & - & - & - & - & - & Asn & - & - & - & - \\
\hline bLH & - & - & - & - & His & - & Gly & Pro & - & Arg & Leu & Ser & Ser & Thr \\
\hline bFSH & - & Thr & Glu & - & His & - & - & Lys & - & Asp & Ser & Asp & Ser & Thr \\
\hline scGTH & Asp- & Cys - & - Thr & - Ile - & - Glu - & - Ser - & -Leu & $-G \ln -$ & - Pro & -Asp- & - Tyr- & -Cys & -Met & - Ser - \\
\hline cGTH & - & - & - & - & - & - & - & - & - & - & Phe & - & - & - \\
\hline sGTH & - & 一 & - & - & - & - & - & - & - & - & Phe & - & Ile & Thr \\
\hline bLH & - & - & Gly & Gly & Pro & Arg & Thr & - & - & Leu & Ala & - & Asp & His \\
\hline bFSH & - & - & - & Val & Arg & Gly & - & Gly & - & Ser & Tyr & - & Ser & Phe \\
\hline scGTH & Gln - & Arg & -Glu - & - Asp & Phe & - Pro & & & & & & & & \\
\hline cGTH & - & - & - & - & - & Leu & & & & & & & & \\
\hline sGTH & - & - & Val & Leu & Thr & Asp- & - Gly & -Asp- & -Met & -Trp & & & & \\
\hline bLH & Pro & Pro & Leu & Pro & Asp & Ile & Leu & & & & & & & \\
\hline bFSH & Arg & Glu & Ile & Lys & Glu & & & & & & & & & \\
\hline
\end{tabular}

Note. sc, silver carp; c, carp; s, salmon; b, bovine; -, residue identical to that of scGTH. References: cGTH from Chang et al. (1988b); sGTH from Trinh et al. (1986); bLH from Maurer (1985); bFSH from Esch et al. (1986). 
TABLE 4

Homology ANALYSIS OF VeRTEBRATE GTHs

\begin{tabular}{ccc}
\hline Subunit & Type of GTH & Homology (\%) \\
\hline$\alpha$ & scGTH vs cGTH & 98 \\
& scGTH vs bLH & 72 \\
$\beta$ & bLH vs hLH & 74 \\
$\beta$ & scGTH vs cGTH & 97 \\
& scGTH vs sGTH & 75 \\
& scGTH vs bLH & 42 \\
& scGTH vs bFSH & 40 \\
& sGTH vs bLH & 41 \\
& sGTH vs bFSH & 35 \\
& bLH vs bFSH & 38 \\
\hline
\end{tabular}

Note. References: $\mathrm{cGTH}-\alpha$ and $\mathrm{cGTH}-\beta$ from Chang et al. (1988b); bLH- $\alpha$ from Cornell and Pierce (1974); bLH- $\beta$ from Maurer (1985); hLH- $\alpha$ from Fiddes and Talmadge (1984); sGTH- $\beta$ from Trinh et al. (1986); bFSH- $\beta$ from Esch et al. (1986).

tionship of the $\beta$ subunit of fish GTH. The data of Tables 3 and 4 indicate that homology between the $\beta$ subunit of fish and mammalian GTH is around $40 \%$, which is close to that between the $\beta$ subunit of $\mathrm{LH}$ and FSH of a given species of mammal. Although the amino acid sequences of the $\beta$ subunit of fish and mammalian GTHs are diversified, all of them contain 12 halfcystines and these residues can be aligned at the same positions.

The homology analyses of the $\alpha$ and $\beta$ subunit between fish and mammalian GTH are summarized in Table 4 . These comparative data gave further indication that the $\alpha$ subunit is conserved while the $\beta$ subunit is diversified during the molecular evolution of vertebrate GTH.

\section{ACKNOWLEDGMENTS}

We express our particular appreciation to Mr. C. S. Chang for his invaluable amino acid determination. This work was supported by the National Science Council, ROC (NSC 77-0203-B001-07).

\section{REFERENCES}

Burzawa-Gerard, E. (1974). Purification d'une hormone gonadotrope hypophysaire de poisson teleosteen, la carpe (Cyprinus carpio L.). Biochimie $53,545-552$.
Chang, C. S., and Liu, C. S. (1988). A picomole-level amino acid analysis by means of gas-phase hydrolysis and DABS-C1/HPLC method. J. Chin. Biochem. Soc. 17, 12-19.

Chang, Y. S., Huang, F. L., Chen, C. T., and Lo, T. B. (1988a). Isolation and properties of the pituitary gonadotropin from silver carp (Hypophthalmichthys molitrix). Int. J. Pept. Protein Res. 31, 150-156.

Chang, Y. S., Huang, C. J., Huang, F. L., and Lo, T. B. (1988b). The primary structures of carp gonadotropin subunits deduced from cDNA nucleotide sequences. Int. J. Pept. Protein Res. 32, $556-564$.

Cornell, J. S., and Pierce, J. G. (1974). Studies on the disulfide bonds of glycoprotein hormones. J. Biol. Chem. 249, 4166-4174.

Donaldson, E. M., Yamazaki, F., Dye, H. M., and Philleo, W. W. (1972). Preparation of gonadotropin from salmon (Oncorhynchus tshawytscha) pituitary glands. Gen. Comp. Endocrinol. 18, 469 481.

Esch, F. S., Mason, A. J., Cooksey, K., Nercads, M., and Shimasaki, S. (1986). Cloning and DNA sequence analysis of the cDNA for the precusor of the $\beta$ chain of bovine follicle stimulating hormone. Proc. Natl. Acad. Sci. USA 83, 6618-6621.

Farmer, S. W., and Papkoff, H. (1977). A teleost (Tilapia mossambica) gonadotropin that resembles luteinizing hormone. Life Sci. 20, 1227-1232.

Fiddes, J. C., and Talmadge, K. (1984). Structure, expression and evolution of the genes for the human glycoprotein hormones. Recent Prog. Horm. Res. 40, 43-78.

Greenwoods, F. C., Hunter, W. M., and Glover, J. S. (1963). The preparation of ${ }^{131}$ I-labelled human growth hormone of high specific radioactivity. Biochem. J. 89, 114-123.

Grunstein, M., and Hogness, D. (1975). Colony hybridization: A method for the isolation of cloned DNAs that contain a specific gene. Proc. Natl. Acad. Sci. USA 72, 3961-3965.

Gubler, U., and Hoffman, B. J. (1983). A simple and very efficient method for generating cDNA library. Gene 25, 263-269.

Hayashi, R. (1974). Carboxypeptidase $Y$ in sequence determination of peptide. In "Methods in Enzymology" (C. H. W. Hirs and S. N. Timosheff, Eds.), Vol. 47, pp. 84-93. Academic Press, New York.

Hewick, R. M., Hunkapillar, M. W., Hood, L. E., and Dreyer, W. J. (1981). A gas-liquid solid phase peptide and protein sequenator. J. Biol. Chem. 256, 7990-7997.

Hunag, F. L., and Chang, Y. S. (1980). The gonadotropic stimulation of androgen production on carp 
testis in vitro. Proc. Natl. Sci. Counc. Repub. China 4, 392-400.

Huang, F. L., Huang, C. J., Lin, S. H., Lo, T. B., and Papkoff, H. (1981). Isolation and characterization of gonadotropin isohormones from the pituitary gland of pike eel (Muraenesox cinereus). Int. J. Pept. Protein Res. 18, 69-78.

Huang, F. L., Chang, Y. S., Chang, G. D., and Lo, T. B. (1982). Properties of subunits of pike eel gonadotropin. Proc. Natl. Sci. Counc. Repub. China 6, 30-36.

Idler, D. R., and Ng, T. B. (1983). Teleost gonadotropins: Isolation, biochemistry and function. In "Fish Physiology"' (W. S. Hoar and D. J. Randell, Eds.), Vol. 9A, pp. 187-221. Academic Press, New York.

Itoh, H., Suzuki, K., and Kawauchi, H. (1988). The complete amino acid sequences of $\beta$-subunits of two distinct chum salmon GTHs. Gen. Comp. Endocrinol. 71, 438.451.

Kidd, V. J., Wallace, R. B., Hakura, K., and Woo, S. L. C. (1983). $\alpha_{1}$-Antitrypsin deficiency detection by direct analysis of the mutation in the gene. Nature (London) 304, 230-234.

Knecht, R., and Chang, J. Y. (1986). Liquid chromatographic determination of amino acids after gas-phase hydrolysis and derivatization with (dimethylamino)azobenzenesulfonyl chloride. Anal. Chem. 58, 2375-2379.

Laemmli, U. K. (1970). Cleavage of structural protein during the assembly of the head of bacteriophage $\mathrm{T}_{4}$. Nature (London) 227, 680-685.

Liu, W. K., Nahm, S. H., Sweeney, C. M., Lamkin, W. M., Baker, H. N., and Ward, D. N. (1972). The primary structure of ovine luteinizing hormone. I. The amino acid sequence of the reduced and $S$-aminoethylated S-subunit (LH- $\alpha$ ). J. Biol. Chem. 247, 4351-4364.

Lowry, O. H., Rosebrough, N. J., Far, A. L., and Rondall, R. J. (1951). Protein measurement with the phenol reagent. J. Biol. Chem. 193, 265-275.

Maurer, R. A. (1985). Analysis of several bovine lutropin $\beta$ subunit cDNAs reveals heterogeneity in nucleotide sequence. J. Biol. Chem. 260, 4684 4687.
Maurer, R. A., Croyle, M. L., and Donelson, J. E. (1984). The sequence of a cloned CDNA for the $\beta$ subunit of bovine thyrotropin predicts a protein containing both $\mathrm{NH}_{2}$ - and $\mathrm{COOH}$-terminal extensions. J. Biol. Chem. 259, 5024-5027.

Pierce, J. G., Faith, M. R., and Donaldson, E. M. (1976). Antibodies to reduced $S$-carboxymethylated alpha subunit of bovine luteinizing hormone and their application to study of the purification of gonadotropin from salmon (Onchohynchus tshawytscha) pituitary glands. Gen. Comp. Endocrinol. 30, 47-60.

Pierce, J. G., and Parsons, T. F. (1981). Glycoprotein hormones: Structure and function. Annu. Rev. Biochem. 50, 465-495.

Rondle, C. J. M., and Morgan, W. T. J. (1955). The determination of glucosamine and galactosamine. Biochem. J. 61, 586-589.

Roser, J. F., Chang, Y. S., Papkoff, H., and Li, C. H. (1984). Development and characterization of a homologous radioimmunoassay for equine prolactin. Proc, Exp. Biol. Med. 175, 510-517.

Sanger, F., Nicklen, S., and Coulson, A. R. (1977). DNA sequencing with chain-terminating inhibitors. Proc. Natl. Acad. Sci. USA 74, 5463-5467.

Suzuki, K., Kawauchi, H., and Nagahama, Y. (1988). Isolation and characterization of subunits from two distinct salmon gonadotropins. Gen. Comp. Endocrinol. 71, 302-306.

Trinh, K. Y., Wong, N. C., Hew, C. L., and Crim, L. W. (1986). Molecular cloning and sequencing of salmon gonadotropin $\beta$ subunit. Eur. J. Biochem. 159, 619-624.

Vaitukaitis, J. L., Roffins, J. B., Nieschlag, E., and Ross, G. T. (1971). A method of producing specific antisera with small dose of immunogen. $J$. Clin. Endocrinol. Metab. 33, 988-991.

Ullrich, A., Shine, J., Chirgwin, J., Pictet, R., Tischer, E., Rutter, W. J., and Goodman, H. M. (1977). Rat insulin genes: Construction of plasmids containing the coding sequences. Science 196, 1313-1319.

Warren, L. (1959). The thiobarbituric acid assay of sialic acid. J. Biol. Chem. 234, 1971-1975.

Winzler, R. J. (1955). Determination of serum glycoproteins. Methods Biochem. Anal. 2, 279-311. 